\title{
REPRESENTATIONS AND INFLUENCE PROCESSES IN GROUPS: TOWARDS A SOCIO-COGNITIVE PERSPECTIVE ON COGNITION IN ORGANIZATION
}

\author{
Florence Allard-Poesi \\ Université Paris-Est, IRG (EA 2354)
}

Scandinavian Journal of Management, 1998, vol.14, $n^{\circ} 4$, pp.395-420.

\begin{abstract}
The cognitive approach of organizations assumes that there exists collective representations in organizations. We critically examine this assumption and propose to adopt a socio-cognitive perspective of collective cognition in organizations. This theoretical stream, that rejects the traditional individual/social dichotomy argues for the study of Social Cognition, which implies a change in the unit of analysis from the individual/social levels to interactions. A collective representation is understood as related to the socio-cognitive dynamics taken place between interacting group members. Communication and influence processes are then critical for the construction of a collective representation. The socio-cognitive perspective and the theory of social influence it proposes may offer new and important insights to everyday thinking and behaving in organizations. They requires however new methodological approaches to study organizational cognition.

Key words: Cognition; Social Representations; Social influence; Group dynamics.
\end{abstract}

Acknowledgements: This paper is supported by a grant of the Fondation Nationale Pour l'Enseignement de la Gestion des Entreprises. Earliers versions of the manuscript were presented at the 4ième Conférence Internationale en Management Stratégique, Paris, 2-4 May 1995, and at the 3rd International Workshop on Managerial and Organizational Cognition, Glasgow, 14-16 June 1995. We would like to thank participants for their comments and remarks. Special thanks to Guje Sevon, Mauri Laukkanen and Nancy Adler for their helpful comments and support. 


\section{REPRESENTATIONS AND INFLUENCE PROCESSES IN GROUPS : \\ TOWARDS A SOCIO-COGNITIVE PERSPECTIVE TO COGNITION IN ORGANIZATION}

\section{INTRODUCTION}

The cognitive perspective, which has been criticized for its methodological bias and conceptual limits (Von Krogh et al., 1995; Schneider and Angelmar, 1993; Laroche and Nioche, 1994), assumes implicitly that a collective representation (generally called a shared or collective cognitive schema) exists in organizations, a variable that could explain numerous organizational phenomena such as action, change, crisis and performance (Johnson, 1986). What does this collective cognitive structure consist of? What are its properties compared to an individual cognitive schema? How does it emerge from the supposedly different representations held by the organizational members?

We first examine these questions in light of the cognitive paradigm. After having underlined the methodological and conceptual limits of this paradigm and referred to some empirical studies whose results question this approach, we argue for the adoption of a socio-cognitive perspective. In particular this perspective leads to a new conception of social influence processes and of the socio-cognitive dynamics in groups, which in turn offers interesting insights into collective cognition in organizations. While not considered exclusively as a cognitive or behavioural conformity mechanism, social influence can lead not only to conformity in groups but also to normalization and to polarization, innovation and change, all appearing as many different emergence processes and forms for a collective cognitive schema in organizations. We contend that such a perspective on cognition reflects more adequately how people behave and think in organizations. It also sheds new light on decision-making, organizational change and learning. However, a socio-cognitive perspective on organizational life requires new methodological approaches and methods.

\section{THE INDIVIDUAL / COLLECTIVE CONNECTION ACCORDING TO THE COGNITIVE PARADIGM}

\section{From individual to organizational cognition}

The cognitive perspective on organizations comes from an Anglo-Saxon research current in cognitive psychology, which assumes that the individual has cognitive structures or schemas which enable him to understand events and situations (Walsh et al., 1988; Codol, 1989; Gioia and Poole, 1984; Harris, 1994). These cognitive structures are usually defined as general 
frames used by the individual to impose structure and thus meaning on information, situations or experiences (Harris, 1994). The basic unit of a cognitive structure is a "cognem" (the smallest cognitive unit), defined either as a concept, a piece of knowledge, an object, an opinion, a proposition, a belief, an attribute or trait of concrete or abstract objects, or an item of information. These units are regarded as being linked together and integrated into sets. The set of all possible cognems and their relationships concerning a specific domain or object, forms a representation (a term used especially by French-speaking psychologists) or a cognitive structure, organization or schema (Codol, 1989; 1969). The meaning of an object or a concept is then encoded in the pattern of relationships occurring in its corresponding schema. Assigning an object, an experience or a person to its corresponding schema consequently permits the perception, interpretation and conceptualization of the environment (Harris, 1994; Lord, 1985), as well as judgements and actions (Montgomery and Svenson, 1989; Kiesler and Sproull, 1982; Lord, 1985) in a very economical way. However, these cognitive schemas are the source of numerous biases. They affect information-processing (Lord, 1985; Kiesler and Sproull, 1982; Louis, 1980), judgement (Walton, 1986), attitude (Calder and Schurr, 1981), decision processes (Montgomery and Svenson, 1989; Isenberg, 1986) and behaviour (Gioia and Poole, 1984; Klimoski and Mohammed, 1994).

Researchers in organizational studies have increasingly adopted this cognitive perspective developed at the individual level, and have incorporated the notion of representation into their theories (Klimoski and Mohammed, 1994). Stubbart (1989) argues that this perspective makes it possible to go beyond a rational perspective of choice in strategy-making and decision processes; Porac and Thomas (1989) use the notion of mental models as a framework for understanding how strategists interpret their competitive environments in order to explain competitive strategy-making; Walton (1986) demonstrates that managers in the same sector use similar schemas of success, indicating that they attach some core meanings to this notion. At a general level researchers consider that bringing the implicit assumptions held by organizational members to the surface, is a first step towards understanding organizational action and managerial decision-making (Walton, 1986), the individual's cognitive performance (Isenberg, 1986) and judgements and behaviours in organizations (Conlon and Stone, 1992; Gioia et al., 1989; Gioia and Sims, 1986). Although the cognitive perspective has been traditionally applied at the individual level, the growing interest it has attracted in organizational studies has led to its extension to the group and organizational levels of analysis.

The cognitive approach has thus been applied to the organizational level in a cognitive paradigm that sees the organization as the result of social constructions based on its members' collective cognitive schema (Allaire and Firsirotu, 1984; Smircich, 1983). In this perspective, 
organizations become frames of reference or networks of subjective meanings which are shared to varying degrees by their members. These systems of shared ideas or beliefs influence organizational members so that their behaviours fit the organizational goals and expectations, and so that organizational action becomes possible (Allaire and Firsirotu, 1984). This notion of "system of shared ideas / beliefs" has been defined in various ways in the literature: as beliefs, understandings that represent credible relations between objects, properties, or ideas (Sproull, 1981); as an ideology, a coherent set of beliefs that binds some people together and explains their world in terms of cause and effect relationships (Beyer, 1981; et al., 1988; Starbuck, 1982); as a dominant logic, a mental map developed through experience (Bettis and Prahalad, 1995; Prahalad and Bettis, 1986); as an interpretative scheme, a schema that maps the experience of the world, identifying both its relevant aspects and how we are to understand them (Poole et al., 1989; Bartunek, 1984; Bartunek and Moch, 1987); as a cognitive system, a set of mental maps that persist over time although organizational members come and go (Hedberg, 1981) etc.

Such systems of shared beliefs are supposed to emerge from shared experiences and interactions among organizational members (Harris, 1994; Porac and Thomas, 1989). On the one hand, individual schemas may become similar as the result of shared experiences and exposure to social cues regarding other people's constructions of reality (Harris, 1994; Porac et al., 1989; Kiesler and Sproull, 1982). On the other hand, common schemas in organizations emerge from interactions and communication among organizational members (Porac et al., 1989; Shrivastava and Schneider, 1984; Schneider and Shrivastava, 1987; Ashforth, 1985; Feldman, 1984; Pfeffer, 1981). Referring to Festinger's social comparison theory (e.g. Gioia and Poole, 1984; Pfeffer and Salancik, 1978; Ashforth, 1985; Pfeffer, 1981; Sproull, 1981; Feldman, 1984), and to normative influence theory (e.g. Bettenhausen and Murningham, 1985; Schein, 1984), researchers regard interactions and communication processes (and especially those involved in decision-making processes - Shrivastava and Schneider, 1984) as resulting in conformity and shared thinking in organizations. Socialization processes and managers' symbolic actions, which more specifically activate these influence processes, are then crucial to the development and maintenance of shared mental models in organizations (Louis, 1980; Pfeffer, 1981; Nystrom and Starbuck, 1984; Sproull, 1981; Beyer, 1981). In order that newcomers should develop adequate schemas, managers must pay attention to these socialization processes (Sproull, 1981; Nystrom and Starbuck, 1984). The public and symbolic rewarding of the desired beliefs and behaviours, and the use of co-workers to indoctrinate newcomers, can help to maintain shared beliefs in organizations. Similarly, if organizations are organized through the development of shared understandings, management's task is to develop such understandings within the organization. This may be accomplished through the use of symbols, ceremonies and language (Pfeffer, 1981). Once created and 
socially shared, these symbols and perceptions of reality can motivate and mobilize organizational members to act, thus ensuring continuous support for the organization (Pfeffer, 1981; Shrivastava and Schneider, 1984).

However, collective representations are enduring and resistant to change. They will affect other organizational variables and processes such as decision processes and strategy-making, organizational action, performance, structure, change and learning. For instance, collective representations polarize attention to specific problems and provide guidelines for interpreting environmental information (Shrivastava and Schneider, 1984; Beyer, 1981; Sapienza, 1985), thus facilitating choices and implementation processes (Klimoski and Mohammed, 1994; Beyer, 1981). At a more general level, common representations influence strategic actions and thus organizational performance (Sapienza, 1985; Thomas et al., 1993). These systems of shared ideas may result in cognitive rigidities and inadequate actions in a changing environment, leading to crisis and low performance (Hall, 1984, 1976; Fahey and Narayanan, 1989: Starbuck, 1982; Huff and Schwenk, in Huff, 1990). Managers are then encouraged to become more aware and to call in question their basic assumptions, when engaged in a decision-making process (Beyer, 1981; Schneider and Shrivastava, 1987). By using dialectical and devil's advocacy approaches in their decision-making processes (Beyer, 1981; Sproull, 1981; Schweiger et al., 1986), managers can evaluate the extent to which their beliefs are facilitating performance. They will then avoid decision biases and increase their creativity (Smircich and Stubbart, 1985).

At the organizational level, shared representations in organizations may inhibit change processes and implementation (Schwenk, 1989; Poole et al., 1989; Gioia et al., 1994; Nystrom and Starbuck, 1984). Organizational change implies a redefinition of the organization's mission and goals, or a substantial change in its properties so as to reflect new orientations (Gioia et al., 1994). It involves the development of new understandings of the organizational goals and their dissemination among organizational members, so that their new schemas fit current organizational experiences (Poole et al., 1989). Previous common schemas, structural and political factors may affect the development of new representations among managers (Schwenk, 1989; Lyles and Schwenk, 1992). These representations also have to be efficiently disseminated among organizational members (Lyles and Schwenk, 1992; Schwenk, 1989). Here managers have to be aware of the previously existing schemas if their mission is to be successful (Bartunek and Moch, 1987). They can associate the perceived crisis with the representations held by organizational members, in order to reveal their inadequacy and to propose new ones. They can also use direct and indirect modes of influence, in order to disseminate their new representations among the organizational members (Gioia et al., 1984; Poole et al., 1989; Bartunek and Moch, 1987). 
Promoting organizational learning requires similar actions. At a very general level, organizational learning may be understood as the process by which organizational members share their schemas in order to form a collective map or an organizational knowledge structure. This system of shared ideas in turn affects members' schemas and representations (Shrivastava, 1983; Hedberg, 1981; Lyles and Schwenk, 1992), and guides individual behaviours and organizational actions (Lee et al., 1992; Fiol, 1994; Fiol and Lyles, 1985). However, previously held representations act as filters for an organization and constrain its learning capacity. Unlearning these old knowledge structures is then necessary, if new ones are to emerge (Hedberg, 1981; Bettis and Prahalad, 1995). Dialectical and devil's advocacy approaches in decision-making processes, as well as debates, exchange and diffusion of ideas (Koenig, 1994; Shrivastava and Schneider, 1984; Smircich and Stubbart, 1985) can facilitate these unlearning processes. The new system of shared ideas leads to actions and environmental responses that will be interpreted according to the new collective schema. These new interpretations in turn affect these representations, resulting in a more or less profound change in the "theories in use" (Schön, 1983) or "dominant logic" (Bettis and Prahalad, 1995) of the organization.

Up to now, the notion of shared ideas and beliefs in organizations has been regarded as crucial to the understanding of decision processes, organizational action and performance, change and learning. However, this central assumption of the cognitive paradigm is being seriously questioned today, by empirical studies on the one hand and conceptual and methodological problems on the other hand.

\section{The need for revising the notion of collective representations in organization.}

Although the cognitive perspective offers new and important insights on organizational life, it does little to account for the emergence and properties of a collective representation in organizations. From a relatively clear concept at the individual level, we seem to have ended up with a very slack and loose concept at the organizational level. Relying on an extensive literature review of group mental models, Klimoski and Mohammed (1994) demonstrate the ambiguities of this notion in organization studies. What form do such collective cognitive structures assume (verbal, spatial, concrete, abstract, images, beliefs)? What is the content (linked to the task, the environment, the others)? What does "sharing" mean: to what extent do group members have to share their individual representations so one can conclude that a collective representation exists? This last question appears even more critical if we consider recent empirical studies that evaluate the extent to which individual representations coincide in organizations (Hugues et al., 1994; Allard-Poesi, 1994; Bougon et al., 1977; Ford and Hegarty, 1984; Fotoni Paradissopoulos, 1994). Altogether, this research reveals that, although 
there may be consensus about some strategic domain or core beliefs among managers, homogeneity or congruence in individual representations in organizational settings cannot be taken for granted (Gray et al., 1985).

Beyond these ambiguities in the concept of collective representation, one may also question the way cognitive phenomena are understood globally in organizational studies. There is often no coincidence between the unit of analysis that is supposed to be organizational, and measurements that rely mainly on aggregates of individual measurements (see for instance James et al., 1988; Bougon et al., 1977). This tends to result in anthropomorphic bias (Schneider and Angelmar, 1993) or cross-level fallacies, i.e. the generalization of interindividual relationships to universal of intercollective ones (Rousseau, 1985; Glick, 1988). On the other hand, research tends to ignore measurement problems and to freely apply the idea of cognitive schema or representation to individuals, groups, organizations or institutions, and this leads to reification bias (Laroche and Nioche, 1994; Spender, 1994). These difficulties come from the implicit assumption of a conceptual isomorphism between the individual and the collective levels of cognition. In fact, it is being assumed that the same functional relationships can be used to represent the two constructs, which are supposed to have the same position in a nomological network (Rousseau, 1985). According to Schneider and Angelmar (1993), we have to search for such a multi-level equivalence. But its merit and its relevance for the study of collective cognition in organization can be legitimately questioned. Influence and the political processes at stake in organizational settings may endow a collective representation with much greater complexity than a schema resulting from an average (cf. Bougon et al., 1977), or from more sophisticated aggregates of individual measurements (cf. Ginsberg, 1990; Dunn and Ginsberg, 1986; Weick and Bougon, 1986; Walsh and Fahey, 1986; et al., 1988). These mathematical artefacts do not take into account the potentially emergent properties of collectivities (Schneider and Angelmar, 1993; Stubbart, 1993). Questioning the implicit isomorphism between the individual and the collective levels of cognition may enable us to capture the distinctive nature and the emergent properties of cognition at the organizational level (Stubbart, 1993).

Similar critiques can be formulated against the conceptualizations of the emergence and development of collective representations in organizations. It has been argued that similarity in organizational members' representations occurs because they experience similar contexts, problems and constraints. Such a conceptualization relies on a determinist view of cognitive phenomena, which could be said to be a contradiction in terms (Lauriol, 1994; Codol, 1989; Moscovici, 1984a). On the other hand, common representations are seen as emerging through mechanisms whereby the individual conforms to the group. Such a conceptualization of influence relies on the idea that organizations are sets of levels (individual, group, organization): the individuals are constrained by the group, which is more or less influenced 
by other organizational factors. This perspective thus tends to ignore the bidirectionality of influence processes (Gioia et al., 1994), and to reproduce anthropomorphic and reification biases.

Altogether, then, it appears that the concept of collective representation not only suffers from lack of clarity but may also be too restrictive to comprehend the nature of collective cognition in organizations: Is there a collective cognitive representation in organizations? What are its properties compared with individual representation, and how does it emerge from the supposedly different representations held by organisational members? The socio-cognitive perspective here offers an interesting alternative approach to the organization as a system of ideas.

\section{THE SOCIO-COGNITIVE PERSPECTIVE ON COLLECTIVE REPRESENTATIONS: KEY ELEMENTS}

\section{The rejection of the individual/social dichotomy and the notion of Social Representation}

A number of research orientations coming from various domains in the social sciences today converge to produce a vision of reality as a "consensual construction elaborated in interactions and communication" (Jodelet, 1989; Allaire and Firsirotu, 1984): from anthropology, Sperber (1989); from sociology, Berger and Luckman (1967); from socio-linguistics, Cicourel (1972); from linguistics, Harré (1981); and from social and cognitive psychology, Moscovici (1989; 88; 1984a; 1984b), Hewstone (1989), Forgas (1981 a; b). Despite differences in their methodological approaches and units of analysis (society for the first of these, the group or the individual for the others), all these research streams reject the individual/social or cognition/social dichotomy. They advocate instead the study of "social cognition", thus implying a change in the research object from individual/organization to interaction.

This interactive view of the cognitive and social aspects has been developed in particular by Moscovici and his colleagues in social psychology. Referring to the works of Piaget and Freud, which question on the one hand the prevailing influence of the social on the individual, and on the other the strict impermeability and the equivalence of these levels, Moscovici (1988; 89; 84a; 84 b) reintroduces the concept of Social Representation. Going beyond the numerous definitions and debates surrounding this notion (See Jodelet, 1989; Moscovici, 1988; Jahoda, 1988), Social Representations can be defined as "processes and products of a social and cognitive elaboration of reality" (Codol, 1989, our translation). This concept must be understood not in terms of its social foundations, but in the sense that its content and working rules depend on interindividual processes: "Representations may be termed 'social' less on account of whether their foundations are individuals or groups, than because they are worked out during processes of exchange and interaction" (Codol, 1984, p. 251). It is in this sense that Social Representations must be distinguished from the concepts of ideology, belief, 
interpretative system, cognitive system, and so on, which are used in organizational cognition research that sees the foundations of these cognitive systems as mainly organizational, and their mode of transmission as unilateral (from the organization to its members). A disctinction is also made relative to the concepts of cognitive schema, cognitive organization or structure, as used by cognitive psychologists for whom cognitive processes are essentially intra-individual (Moscovici, 1988; Codol, 1969).

\section{Towards Social Cognition}

Extricating ourselves from the individual/social dichotomy and reconsidering in this light the concept of Social Representations make it possible to put an end to some of the unquestioned assumptions of the cognitive and social fields:

- The social aspects do not only constrain: we must recognize that in one way or another, representations are generated and modified, and that the individual contributes to these processes. Vergès et al. (1987, p. 51) underline that "The social actor is a true creator... He is admittedly limited by his pre-constructs, but he creates his own discourse. What he says is singular. It is a true emergence. Thus, the individual is not a reflection; he constructs his own schemas and objects" (our translation).

- Cognition is not only an intra-individual process: it is determined by elements that are fundamentally social. It is contextualized and often has a social end, in particular when it is expressed in discourse (Harré, 1981). "Our knowledge is socially structured and transmitted from the first days of our life and they are coloured by the values, motivations and norms of our social environment in adulthood" (Forgas, 1981a, p. 2). And if individuals continually construct and reconstruct their representations, they do not do it alone, but in interaction with others (Windish, 1989, p. 180).

Recent empirical works on the cognitive development of children (Bruner and Sherwood, 1981; Doise and Mugny, 1979; and Mackie, 1981) on the one hand, and on the systems of representation in group situations (Abric, 1984; 1989; et al., 1975; Codol, 1974; 1984) on the other, demonstrate this permeability of the social and cognitive dimensions.

As cognitive phenomena cannot be reduced to intra-individual processes (Forgas, $1981 \mathrm{a} ; \mathrm{b}$ ), and inversely, interactions are influenced by the representations held by group members (Codol, 1974; 1984; Abric, 1984; 1989), a collective representation or schema appears to be inseparable from interactions. These interactions have to be understood as the process and result of the social construction of reality (Jodelet, 1989). Such a conceptualization leads to the examination a collective cognitive schema not as a phenomenon in itself, but as something "always in the making, in the context of interrelations and actions ... that are themselves always in the making" (Moscovici, 1988, p. 219). This means shifting the emphasis from the phenomenon in itself to communication (Moscovici, 1988). Communication, through the 
influence processes it activates, enables individual representations to converge, and something individual to become social (Moscovici, 1988; Jodelet, 1989). However, again, social influence must not be understood here in a unilateral way, as a conforming process. The recognition that the social and cognitive dimensions interact, calls for a reconceptualization of the process of social influence.

\section{Social influence and its contribution to the understanding of collective cognition}

Social influence has in fact long been regarded as a conforming process: the individual modifies his or her behaviour or attitude to those of the group (Levine and Pavelchak, 1984). The spectacular experiments of Asch in the fifties demonstrated in particular that the individual tends to conform to the majority response, even if it expresses opinions contrary to objective physical evidence (Moscovici and Faucheux, 1972). This conformity process has been theoretically explained by informational influence theory (Levine and Pavelchak, 1984; Moscovici and Faucheux, 1972) or normative influence theory (Marc and Picard, 1989; Levine and Pavelchak, 1984). According to Moscovici and his colleagues, such a perspective on influence relies on too restrictive an approach to the relationships between the source and the target of influence (Moscovici and Faucheux, 1972; and Neve, 1971; Doms and Moscovici, 1984). The majority (or the source of authority) is considered as the norm-sender and is identified with the group, and the minority is seen as the norm-receiver and is equivalent to the "deviants" (Moscovici and Faucheux, 1972; Doms and Moscovici, 1984; Levine and Pavelchak, 1984). In this perspective, the minority can only accept or reject what is imposed by the group. Such a conception of social influence thus relies on the idea that interactions have to lead to conformity if the group is to survive (Moscovici and Faucheux, 1972). However, "Far from being only an element of solidarity and psychological equilibrium, conformity may become, in a long run, a source of instability and conflict". Thus "the analysis of social influence which finds its expression in social change is just as legitimate a concern" (Moscovici and Faucheux, 1972, p. 155). In this perspective, we need a theory that does not see social influence as a unilateral process, but understands it as dynamic and symmetrical (Doise and Moscovici, 1984; Moscovici and Doise, 1994; Moscovici and Faucheux, 1972; Moscovici et al., 1969).

\section{A socio-cognitive perspective on Social Influence}

\section{Social influence as a conflict and negotiation process}

If we regard every group member as both source and target of influence, and accept that influence processes can result in innovation and change, how do we conceptualize social influence? What are the key variables and mechanisms underlying this process? The presence of a minority in a group, which strives to introduce or create new ways of thinking or behaving, or to modify existing beliefs, is a key variable that may allow for innovation and 
change (Doms and Moscovici, 1984; Moscovici and Faucheux, 1972; Levine and Pavelchak, 1984). By introducing divergent viewpoints concerning the same social object under discussion, a nomic and active minority in fact creates a socio-cognitive conflict. This conflict can admittedly lead to a rupture in the group, but in most cases individuals feel compelled to eliminate divergencies and to make concessions. Social influence is then no longer tantamount to an information exchange process intended to reduce environment uncertainty, as social comparison theory assumes; it is a process of conflict and negotiation. Social influence and its outcomes correspond to different forms of socio-cognitive conflict and to different ways of treating this: it is necessary to talk social influences (Doms and Moscovici, 1984; Moscovici and Faucheux, 1972; Doise and Moscovici, 1994).

In this perspective, the role of contextual factors has to be taken into account: the adequacy of opinions expressed relative to current thinking (Paicheler, 1978; 1979), the norms induced by the task (Moscovici and Lage, 1978), the interaction style of the participants (rigid vs. flexible) and the way conflict between divergent answers is solved (Mugny and Papastamou, 1979). All these factors will have a key role in the outcome of influence, and thus in the emergence of a consensual view of reality. As influence processes and their results depend on the intensity and forms of the socio-cognitive conflicts during interactions, every type of influence will correspond to a specific way of treating the conflict. In this light, conformity appears as one possible result of influence among others in the group dynamics. Depending on the various socio-cognitive dynamics occuring between group members - and especially on the type of conflict created during interactions, the kind of participative mode adopted by the group (formal vs. informal), the consistency of the viewpoints expressed by members, their implications and the way conflict is solved (control, rejection, avoidance or negotiation) - the forms of consensus achieved and thus the collective representation developed, will be quite different (Doise and Moscovici, 1994; Moscovici and Faucheux, 1972).

Conformity, normalization and polarization as forms of socio-cognitive conflict and negotiation processes.

Conformity as conflict control or rejection

Conformity is defined as "a change in the individual or subgroup behaviour or opinions towards legitimate rules and expectations of the group, irrespective of initial differences" (Moscovici and Faucheux, 1972, p. 166). This process is liable to emerge when the minority has no counter-norm to invoke. In this case, the majority members have no reason to make concessions, as the minority lacks internal consistency; the minority will be either converted or rejected (Levine and Pavelchak, 1984). However such a process requires very specific conditions. In particular, the group has to be "closed" and to represent Asch's group characteristics: there is a "correct" answer to the task, the answers of the minority and the majority diverge significantly, the majority is interindividually consistent, communication of 
judgements only is permissible between interacting participants (they cannot discuss their viewpoints) and the social constraint does not appear to be intentional - which distinguishes conformity from obedience - (Moscovici and Faucheux, 1972). However, when the majority members diversify some of their responses, the majority appears less consistent and less committed to its judgements. In this case, the minority feels less obliged to accept the majority answer, and is more liable to move towards a "compromise" response.

\section{Normalization as conflict-avoidance}

"Normalization defines the pressure each exerts on the other during an interaction, with the aim of reaching either a judgement acceptable to all individuals or one which approaches complete acceptability" (Moscovici and Faucheux, 1972, p. 171). This is accomplished by suppressing differences and levelling off at the lowest common denominator (Moscovici and Faucheux, 1972). This mechanism is liable to arise when the participants are equal in their capacities and competencies so that no-one can legitimately impose their viewpoint on the others, when they are not very involved in the issue or committed to any position concerning it, and/or when the object of the judgement has little significance or is unknown to most people in the group (for instance judgements of weight, colour, smell etc., as opposed to something charged with value). In such cases, as nobody feels legitimated to adhere rigidly to their opinion, participants will avoid extreme positions and will adopt judgements approximating those of the others. A tacit negotiation takes place, and answers are coordinated so that conflict is avoided. The group members' answers converge towards an averaging response as opposed to an extreme one (Moscovici and Faucheux, 1972; Doise and Moscovici, 1994; Moscovici and Zavalloni, 1969). This leads to a "groupal and non-critical thinking", a "shared illusion of unanimity that comes from the self-censure of everybody and that increases because of the assumption that 'who doesn't disagree agrees' " (Doise and Moscovici, 1984, p. 215, our translation).

In this perspective, anything that reduces the intensity and frequency of the interactions will tend - since it also reduces the opportunities for group members to express divergent viewpoints and lessens their involvement in the decision process - to produce what Moscovici and Doise (1994) call "normalized participation" between group members. This participative mode, which is liable to emerge in a formal relationships context, will lead to conflict-avoidance and, consequently, to a compromise consensus. However, if sufficient divergencies are expressed and group members commit themselves in the decision-making process, interactions will produce a change, a polarized answer.

\section{$\underline{\text { Polarization as conflict-creation and resolution. }}$}


Thus, if all participants express themselves freely in the group, influence processes will result not in an averaging of the members' initial positions, but in a specific answer. This collective result is produced by true collaboration between group members; it is close to the values they initially shared and tends to be more extreme than that produced by an averaging of the initial individual positions (Moscovici and Doise, 1994). Far from being a particular phenomenon reduced to very specific conditions, polarization - which has been found in the field of attitudes (Moscovici and Zavalloni, 1969; Myers and Bishops, 1971), in judgements about facts, perceptions of persons, jury and ethical decisions, and risk taking (see Lamm and Myers, 1976, for a review) - appears to be a general process (Doise and Moscovici, 1984).

In fact every decision process, be it individual or collective, leads the individuals involved to look for persuasive arguments which enable them to justify their choices. In seeking these arguments, they become involved in the task they have to undertake (Moscovici and Zavalloni, 1969). In a context of free interactions, the expression of divergent viewpoints, opinions, judgements and ideas in the group will result in conflict - in Lewinian terms, the group "thaws". This conflict further increases the participants' commitment to the task. According to Doise and Moscovici (1994), as the group strives to reach agreement by making reciprocal concessions, the individuals express preferences and alternatives in order to influence each other. One of the most economical ways of reaching agreement is to increase the common basis for argumentation between the participants. As a result of the sharing and of the controversies and new combinations of elements, even people who did not know each other before will find some ideas and meanings that they hold in common. The common elements which they discover will then serve as a basis for consensus. However, this common basis does not result from an elementary arithmetical sum of positive and negative arguments, but from series of exchanges, debates and influences. By way of these processes the dimensions held in common are revealed and become more noticeable, so that the whole cognitive field becomes more organized for each group member (see Moscovici and Zavalloni, 1969; Codol, 1974; 1984 for empirical demonstrations).

Various empirical studies tend to confirm such a theoretical approach to the polarization process: the group members' involvement in the task (Vinokur and Burnstein, 1976; Burnstein and Vinokur, 1973; Neve and Gautier, 1977), the intensity of the socio-cognitive conflict due in particular to the heterogeneity of the initial individual positions (Moscovici and Zavalloni, 1969; Paicheler, 1976; 1977), the participative mode - formal vs. informal - (Doise and Moscovici 1994; Forgas, 1977), all these play a crucial role in setting up the social relationships between the group members (see Appendix 1 for a recapitulation of these studies). And these relationships are a key factor in the perceptions and judgements of the participants, in their cognitive activities as well as in the result of the influence processes 
(Doise and Moscovici, 1994). Thus, the reconceptualization of social influence allows us to recognize different socio-cognitive processes and phenomena in groups: conformity, normalization and polarization, all represent different emergence processes and forms for the collective representations in the organization. Up to now, we have been considering social influence in its interindividual and group manifestations. But social influence also results in a more or less pronounced cognitive restructuring at the individual level.

\section{Forms of Social influence and intra-individual effects: Compliance vs. conversion}

The opinions, interests and representations expressed during group discussions belong to the level of social responses. It is necessary however to distinguish between what belongs to the private (or latent) level, that is to say the cognitive structure underlying the social response, and the public or manifest level (Paicheler and Moscovici, 1984). Such a distinction enables us to appreciate that there can be a public consensus in a group without private acceptance, which corresponds to compliance behaviour. On the other hand, social influence may lead to private but not public acceptance, which reveals conversion behaviour. Compliance and conversion behaviours, which have been revealed empirically in the field of perceptual judgements (Moscovici, Lage and Naffrechoux, 1969; Moscovici, 1981; et al., 1981) and of opinions and attitudes (Mugny, Pierrhumbert and Zubel, 1972; and see Appendix 2 below), force us to take into account the potential discrepancy between what is thought and what is said in social life. The limits to the majority influence in compliance and the power of the minority influence in conversion have to be considered, the more so because the question of the externalization of the private/latent level to the social/public one, has not yet been much investigated (Paicheler and Moscovici, 1984).

This set of conceptual and empirical elements concerning social influence processes in groups (recapitulated in Appendices 1 and 2) offers new insights regarding our conception of the individual/collective connection, and hence to our conceptualization of collective representations in organizations. A collective representation is no longer limited to an intersection point or an average of static individual schemas nor to a conforming social response. We can assume that a collective representation in an organization may exhibit different forms, different emergence processes and different relationships with the individual level of cognition, depending in particular on the participative mode or the relationships between organizational members:

- A collective representation may correspond to a majority response (in conformity). In that case there is no correspondence between the group response and some of the members' (the deviants) individual representations. However, these may benefit from the conversion behaviour of other members at the private level. 
- A collective representation may be equivalent to an average position, to which nobody really adheres (in normalization).

- Or it may be equivalent to a new position which has been developed by means of real collaborative decision work between group members, and which implies a real cognitive restructuring not only at the social but also at the private level.

Further, the distinction between the manifest/public and latent/private levels underlines the potentially evolutionary nature of collective cognitive representations over time, especially if the minority beliefs are expressed consistently at the public level, which may lead to innovation and change in the organization.

\section{DISCUSSION AND CONCLUSION}

\section{On the nature of collective representations in organizations}

Table 1 summarizes the cognitive and the socio-cognitive perspectives on collective representations in organizations.

Table 1.

The cognitive and the socio-cognitive perspectives on collective representations in organizations

\begin{tabular}{|c|c|c|}
\hline Conception of: & Cognitive perspective & Socio-cognitive perspective \\
\hline The organization & $\begin{array}{l}\text { Sets of individual, group and } \\
\text { organizational levels that influence } \\
\text { each other causally }\end{array}$ & $\begin{array}{l}\text { Continuous collective construction } \\
\text { through interactions among } \\
\text { individuals that imply cognitive and } \\
\text { social dimensions }\end{array}$ \\
\hline $\begin{array}{l}\text { Collective } \\
\text { representation }\end{array}$ & Precondition for organizing & Part of the organizing process \\
\hline Manifestation & $\begin{array}{l}\text { Constituted by the common } \\
\text { knowledge shared by organizational } \\
\text { members }\end{array}$ & $\begin{array}{l}\text { Manifested and constructed in and } \\
\text { through interactions }\end{array}$ \\
\hline \multirow[t]{2}{*}{ Characteristics } & $\begin{array}{l}\text { An enduring cultural phenomenon, } \\
\text { slow and difficult to change }\end{array}$ & $\begin{array}{l}\text { Contents and working rules depend } \\
\text { on interindividual processes } \\
\text { More or less enduring, depending on } \\
\text { contextual factors and the } \\
\text { socio-cognitive dynamics during the } \\
\text { interactions }\end{array}$ \\
\hline & $\begin{array}{l}\text { Influencing the decision processes, } \\
\text { actions, change and learning in the } \\
\text { organization }\end{array}$ & $\begin{array}{l}\text { Part of the decision, change and } \\
\text { learning processes in the } \\
\text { organization }\end{array}$ \\
\hline Emergence process & $\begin{array}{l}\text { Members' sharing of similar } \\
\text { experiences, problems and situations } \\
\text { Interactions which lead to }\end{array}$ & $\begin{array}{l}\text { Influence processes and the way } \\
\text { conflict is solved during } \\
\text { interactions, which may lead to }\end{array}$ \\
\hline
\end{tabular}




\begin{tabular}{|l|l|l|}
\hline & $\begin{array}{l}\text { conformity by way of informational } \\
\text { and normative influence }\end{array}$ & $\begin{array}{l}\text { conformity, normalization or } \\
\text { innovation }\end{array}$ \\
\hline
\end{tabular}

At a general level the socio-cognitive perspective highlights the mutually permeable character of the social and cognitive fields. In this perspective, collective representations have to be understood as expressed and constructed in and through interactions between organizational members. They are not an enduring cultural phenomenon to be activated during interactions. Social influence, by allowing individual representations to converge and letting something individual become something social, has a crucial role in this process. Social influence, regarded as a form of conflict and negotiation, may in fact result in conformity in members' answers, in normalization or change. These processes and results will lead to different types of collective representations: more or less organized, and more or less tightly coupled to the members' representations. Unlike the cognitive approach, this theoretical framework thus suggests that:

- Various mental representations may exist in organizations: between interacting subgroups, as has already been evidenced by some empirical studies on culture (Rentsch, 1990; Jermier et al., 1991), and among members of the same board (cf. Hugues et al., 1994; Allard-Poesi, 1994; Fotoni Paradissopoulos, 1994).

- These representations are continuously changing, especially when minority beliefs are expressed consistently at the public level and when a negotiation process occurs between these deviants and the majority;

- Organizational members develop different forms of collective representations, depending on the socio-cognitive processes that take place during their interactions.

These phenomena depend not only on the representations previously held by organizational members, but also on their involvement in the task, on their participative mode during a decision process, and on the norms induced by their tasks and by the social context. These dimensions will result in various forms of socio-cognitive conflict, leading to different kinds of influence processes and different forms for the collective representations.

Such a conceptualization of cognition seems to reflect more adequately what everyone experiences in organizations, namely different ideas about decision to take; influence among members of the same board, among departments or among main coalitions; conflict-avoidance during a decision-process, as well as continuous change in the views held by organizational members, which can lead to innovation and change. These ideas are certainly not new, but they depart from the cognitive perspective that has led us to think of organizations as communities of thinking. The socio-cognitive perspective allows us to recognize that in everyday organization life people do not mention their opinions, do change their views, do influence each other, and do continually reconstruct their representations. Such 
an approach to cognition not only gives a more accurate picture of organizational life, but also sheds new light on change and learning. 


\section{A socio-cognitive perspective on decision-processes, change and learning in organizations.}

A socio-cognitive perspective on decision processes in organizations.

The socio-cognitive perspective goes beyond the pure cognitive or political approaches to strategic decision-making which seem too restrictive (Laroche, 1995; Walsh and Fahey, 1986). Such approaches tend to consider decision-making as an outcome of either cognitive or socio-political variables. When both the political and cognitive dimensions are taken into account, they are envisaged in terms of sets of variables which influence each other causally and diachronically: the socio-political structure of a decision-making group is regarded as affecting the interactions between group members, which in turn will influence the development of a shared knowledge structure (see for instance, Ward and Reingen, 1990; Whitney and Smith, 1985; Walsh et al., 1988; Schwenk, 1989). These approaches may be termed "socio-cognitive", as they take into account the cognitive and the social dimensions that are at stake during the decision process. However, they depart from the socio-cognitive perspective presented here: they do not consider that social and cognitive dimensions interact during the decision-making process itself.

These dimensions should not be regarded as given, or one may miss important aspects of the decision process, and even misinterpret its outcomes. For instance, the final agreement of a decision group may result from interactions dominated by highly formal relationships between participants who were not particularly committed to the decision process. Or it may be the product of an informal participative mode between involved group members, which has produced conflicts and negotiation processes. Thus, depending on its actual emergence process, a final consensus may or may not reveal private agreement of the part of group members. This dimension may also have an impact on the future implementation of the decision (Whitney and Smith, 1983), and on the organizational performance (Bourgeois, 1980). As far as the interpretation of consensus in decision-making groups is concerned, Fiol (1994) notes that the link between consensus and performance has led to conflicting results (see, for instance, Bourgeois, 1980; Schweiger et al., 1986). Fiol suggests that different dimensions of consensus should be taken into account, in order to clarify the link between these variables. In our opinion, it may be more fruitful to try to specify what kind of consensus was obtained: is it a compromise response, which does not actually reflect any individual representation? In this case, it is understandable that the decision will be poorly implemented. Or does the consensus obtained reveal the majority viewpoints? If this is the case, some passive resistance from the minority is to be expected. Or does the decision result from a true collaborative effort between the participants, who have expressed their conflicting views and have striven to reach an agreement through negotiation, argumentation and counter-argumentation? In this case, group members have involved themselves in the decision process, and the final consensus reflects, at least in part, their representations of the situation. 
So they will certainly feel more motivated to implement the decision. The socio-cognitive perspective, which specifies the conditions, processes and outcomes of interactions between group members, sheds new light on the socio-cognitive dynamics involved in a decision-making process.

It may also have interesting managerial implications. Contrary to the arguments of the cognitive approach, organizations cannot be envisaged in terms of a system of shared ideas and beliefs among their members. Organizations imply diversity in meanings and representations. Far from inhibiting consensus in decision-making, such cognitive diversity enables new collective representations to emerge, in so far as participants are involved in the decision-making process and express their divergent viewpoints. This implies not only promoting diversity in thinking, but also encouraging the free expression of opinions and judgements in the organization. This may be accomplished with the help of self-organized groups, by asking for voluntary participation in a task, and by promoting informal relationships and low-level decisions and autonomy in the organization.

\section{A socio-cognitive perspective on organizational change and learning}

The socio-cognitive approach also enables us to go beyond a cognitive perspective on organizational change and learning. Although referring to Berger and Luckman's notion of "a socially constructed reality", the cognitive perspective understands organizational representations as variables that influence and are influenced by political, organizational and structural dimensions in a causal manner (see, for instance, Bartunek's model of change in organizational schemas, structure and actions, 1984; Schwenk's model of organizational change, 1989). At a very general level, organizational learning and change are understood as transition processes, from one state of equilibrium in the collective cognitive schemes to another.

The notion of social representations challenges these assumptions. As noted above, social representations should be examined not as a phenomenon in themselves but as always in the making (Moscovici, 1988). If some of their elements are perhaps more stable than others elements which are called core elements due to their cognitive centrality, as opposed to peripheral ones which are more related to actions and are unstable (Flament, 1989) -representations which are intrinsically linked to interactions in a social group are continuously changing. In this construction process the degree of change may be more or less pronounced, according to the degree of inconsistency between the practices of group members and their representations, and to the influence of subgroups or individuals whose representations are different (Flament, 1989). In this perspective, change and learning can be envisaged as continually involved in organizations. The main issue then may not be why 
change and learning occur in organizations, but to what extent they do: To what extent do change and learning processes occur in individual and collective representations in organizations? What is their content like, and their structure? How do these changes relate to practice, and to the socio-cognitive dynamics that take place among organizational members?

As regards these change processes, the theory of social influence challenges the idea of a unilateral influence flowing from the top management group to other organizational stakeholders who are supposed to receive it passively. If instead influence is regarded as symmetric, the idea that top management first constructs a new collective representation and then tries to disseminate it to other organizational members, appears artificial. A socio-cognitive perspective on influence compels us to recognize that managers not only influence other organizational members, but are also influenced by them, simply through everyday interactions. Managers should be aware here that conflict and negotiation processes, as opposed to conflict-avoidance and control, can generate new ideas and representations to which other organizational members may adhere. Further, if the representations of organizational members are continually changing, rather than remaining stable and resistent to change, solutions such as firing managers and hiring new ones to promote change in the organization (cf. Nystrom and Starbuck, 1984) are questionable. Even though such solutions may have a powerful symbolic value and may promote the idea that change is happening in the organization, they cannot be legitimized by cognitive rigidities: people are not so stupid.

The socio-cognitive perspective also offers new insights on some aspects of organizational learning. That organizational learning should not be conceived as the sum of individual learning is well established (Fiol and Lyles, 1985; Hedberg, 1981; Fiol, 1994). It is also sometimes argued that individual learning is a necessary condition for organizational learning (Hedberg, 1981). The theory of social influence presented here seriously questions this assumption, as it shows that the whole may be more than the sum of the parts (for instance, when a group polarizes). In this perspective, it could be envisaged that a group learns before (or simultaneously with) its members. The socio-cognitive approach also recognizes the key role of minority behaviour in conflict-creation and influence processes, as has been underlined by some researchers on innovation processes and diffusion (Bouwen and Fry, 1991; Garud and Rappa, 1994). The socio-cognitive approach may also help us to understand more about innovation processes in organizations - why, for instance, some innovative ideas are diffused and implemented while others are not. Here again, promoting informal relationships, low-level decision-making and autonomy, and seeking voluntary participation in a project, may encourage the free expression of divergent ideas and negotiation processes. These, in turn, may foster the group members' involvement in the task, and lead to a true collaborative effort which allows new representations to emerge. 
The socio-cognitive perspective not only sheds new light on organizational life; it also makes us reconsider the way managerial and organizational cognition scholars apprehend cognition in organization, namely in terms of the research design and methodological approaches used on the one hand, and in terms of the methods adopted to elicit and analyse the representations on the other.

\section{The study of collective representations in organizations}

The understanding of collective representations in organizations implies that we first try to describe these representations in various settings and in all their complexity. The comparison of these descriptions may help us to comprehend collective representations and to find regularities, so as to build a general theory (Moscovici, 1984b). What kind of methodological approaches can be used to describe collective representations in organizations?

\section{A socio-cognitive approach to cognition}

If we regard collective representations as non-reproducible in laboratory settings, then a field observation approach seems as a relevant alternative (Deconchy, 1981). Collective representations can then be studied longitudinally, in situ, and in the context of various types of interactions: decision-making, informal meetings, day-to-day interactions, and so on (Moscovici, 1984b). The socio-cognitive approach also leads to the adoption of an interactionist perspective on organizations, whereby the organization is viewed as a continuous collective construction evolving and developing in interactions. Interactions, and communication in particular, activate cognitive and social dynamics which allow organizational members to develop realities and representations of these realities. Small groups (for instance decision-making groups, SMED, etc.), which permit an in-depth analysis of these dynamics, can be regarded as a relevant level of analysis for the study of collective representations in organizations. Attention must be paid here to the initial conditions and the processes occurring during the group interactions. Did group members have very different representations of reality before the group work started? Did they commit themselves to the task? What are the norms induced by the task and the social context? What kind of relationships exist between these people? And so on. The specification of these dimensions makes it possible to interpret the collective representation developed and to establish the validity of the results obtained, particularly if different groups are studied and compared (Yin, 1990). In such contexts, how can collective representations be investigated?

\section{Interactions as the unit of analysis}

Collective representations have been understood as being always in the making, and as occurring in interactions that are themselves also always in the making (Moscovici, 1988). In this perspective, the study of collective representations - or, more generally - of social 
cognition, can no longer be limited to the investigation of the "shared" beliefs or other aggregates of individual measurements: The socio-cognitive theory of social influence convincingly demonstrates that "the whole is different from the sum of its parts". The rejection of the individual/social or cognitive/social dichotomy requires us to consider interactions as the unit of analysis. Particular attention must be paid here to communication, which through the influence processes that it activates, allows something individual to become social (Jodelet, 1989). More precisely, the points of agreement and disagreement expressed during the group interactions can be seen as a manifestation of the development of a collective representation of reality. The main grounds serving as a basis for consensus in the group can then be discovered. It may also be inferred from the group decisions and behaviours (Langfield-Smith, 1992).

However, as influence processes during the interactions affect the individual representations differently, a study of the kind and the form of the collective representations developed calls for an investigation of the individual representations over time. Does the collective representation developed during the interactions result from conformity or normalization behaviour? Or does it reveal a true collaborative effort between the group members, which has given rise to a cognitive restructuring at the individual and public levels? Such questions mean that we need to investigate the similarity of group member representations over time, and to compare the beliefs on which participants agreed during the group work with those reappropriated at the individual level. It is then possible to determine the influence of the interactions on the individual representations and the kind of collective representations achieved during the group interactions. In sum, a study of collective representations requires a multi-level and processual approach.

Methodological approaches to eliciting and analysing individual and collective representations.

Various types of methods may be suggested for eliciting and studying individual and collective representations: cognitive mapping (Axelrod, 1976, Cossette and Audet, 1992), content analysis (Weber, 1990), argument mapping, semiotic analysis (Huff, 1990), among others. However, if we want to study these representations accurately and to compare the individual and collective levels elicited, some guidelines may be useful. First, individual representations have to be elicited from discourses produced by non-intrusive techniques. This can increase the validity of the representations obtained. For instance, these may be established by in-depth interviews conducted in a such way as to avoid suggesting anything to the respondent which might become part of his representations (Cossette and Audet, 1992; Cossette, 1994). Other techniques which anchor the interviewer's questions to the last respondent's answers may also be used (cf. Cossette, 1993; Laukkanen, 1992). Secondly, as 
representations have "practical aims" (Jodelet, 1989), the domain or object represented must be meaningful to the respondent. In the same vein, the established representation can be presented to the respondent to allow him to assess the extent to which it properly represents his own vision; It must also be guaranteed that the data will remain confidential. These guidelines should ensure that the representation obtained is "credible" to the subject (Cossette, 1994).

Apart from these elements, which have already been addressed elsewhere (cf. Cossette, 1994; and Audet, 1992; Laukkanen, 1992; Eden et al., 1983; 1992), the method used to establish the individual representations must be applicable to the interactions. The comparison of the beliefs contained in individual representations and those expressed during the group interaction will then be possible. Here it is worth noting that, even in social psychology studies, few techniques of representation at the individual level have been developed or applied to interactions data. The ambiguity of discourse, especially in a small-group context, calls for the development and testing of specific processing techniques and coding methods. These could make it possible to investigate the content of the beliefs expressed as well as the form of communication (agreements, disagreements), so that the common ground developed during the interactions can be revealed. Fiol's (1994) research on communication during a joint-venture process can be regarded as a good example of such an undertaking.

Once the individual and collective representations have been elicited, their analysis also calls for some precautions. As far as the comparison of individual representations is concerned (over time, between subjects), the analysis must be applied to both the content and the structure of the representations: "After all, what we think is not so distinct from how we think" (Moscovici, 1984b, p. 87). Secondly, quantitative and qualitative methods can be used to evaluate similarities in individual representations. However, quantitative approaches - such as mutidimensional scaling (Walton, 1986), factor and cluster analysis (Doise et al., 1992), distance and similarity measures (Markoczy et al., 1992; Daniels et al., 1993) - may be criticized for relying on an "atomistic" perspective of representation (Jenkins, 1994) and for their lack of validity. More qualitative methods are thus needed. For instance, independent judges can be asked to evaluate the similarity of pairs of representations (Daniels et al., 1993). Or, the researcher can select some core elements in the individual representations, and compare their sub-representations by different subjects (see, for example, domain map analysis for causal mapping, Laukkanen, 1994). Or, the dimensions or the core elements around which the individuals organize their representations can be elicited by cluster analysis, and then characterized in order to compare them between subjects. 
These methods make it possible not only to compare the individual representations over time and between subjects, but also to evaluate the extent to which the subjects develop a common ground for representing their world. Once these common dimensions, and more specifically the beliefs shared by a majority, a minority or by all group members before and after the interactions have been noted, they can be compared with the common elements emerging during the interactions. The representations developed during the interactions can then be characterized. For instance, by comparing the beliefs on which a majority of subjects agreed during the interactions with those shared after the interactions, we can evaluate the extent to which the consensus obtained during the interaction was a surface or a latent one. The study of the emergence process and of the nature of collective representations in organizations also requires that the dynamics of the content and the form of the discussions be investigated further. How do people collectively make sense of their world? Do they anchor their thinking in examples and situations which they have experienced, or in some more abstract elements (Klimoski and Mohammed, 1994)? Do they deal with one problem after another, or do they think recursively? On what aspects of reality do they easily come to an agreement - on the interpretation of reality or on ways of modifying it? How were conflicts expressed and solved? Do people avoid divergencies? Or do they negotiate? With a few exceptions (Fiol, 1994; Langfield-Smith, 1992; Sawy and Pauchant, 1988), not many researchers have investigated these dimensions. Here again, specific methods and coding rules are needed.

Thus, to sum up, a socio-cognitive approach to cognition in organizations appears to call for (a) field observation approaches focusing on small groups as the level of analysis; (b) the investigation of both individual representations and the content and form of their interactions over time, (c) using non-intrusive elicitation techniques and methods which take into account the content and structure of the representations.

If organizational life is largely made up of interactions, then such approaches should be able to shed new light on such aspects as have hitherto been neglected in organization studies.

\section{A concluding comment}

I have tried to demonstrate here that the socio-cognitive approach can help to enhance our understanding of cognitive (or rather, socio-cognitive) life in organizations. It even prevents us from adopting an "all-cognitive approach" which cannot be beneficial (Laroche and Nioche, 1994). More generally, this perspective challenges the way we conceptualize issues related to cognition in organizations. It not only questions some implicit assumptions regarding the collective and individual levels of analysis we adhere to, but also pushes us to re-examine other dichotomies such as structure/process, dynamic/static, diversity/uniformity 
and cognitive/organizational outcomes, that are not always helpful. The socio-cognitive perspective thus provides an interesting framework for capturing and comprehending everyday ideas and behaviours in organizations. 


\section{BIBLIOGRAPHY}

Abric, J. C., L'étude expérimentale des représentations sociales. In: D. Jodelet, Les représentations sociales (Paris: Presses Universitaires de France, 1989).

Abric, J. C., A theorical and experimental approach to the study of social representations in a situation of interaction. In: R. M. Farr and S. Moscovici, Social Representations (Cambridge: Cambridge university Press, 1984), pp. 169-183.

Abric, J. C. and Vacherot, G., Méthodologie et étude expérimentale des Représentations Sociales: Tâche, partenaire et comportement en situation de jeu, Bulletin de Psychologie (1975), №29, pp. 735-746.

Allaire,Y. and Firsirotu, M. E., Theories of Organizational culture, Organization Studies (1984), No5(3), pp. 193-226.

Allard-Poesi, F., From individual causal maps to a collective causal map: An exploratory Study (Paper presented to the 2nd International Workshop on Managerial and Organizational Cognition, Brussels, Belgium, May 26-27, 1994).

Ashforth, B.E., Climate formations: Issues and extensions, Academy of Management Review (1985), $\mathrm{N}^{\circ} 10(4)$, pp. 837-847.

Axelrod, R., The cognitive maps of political elites (Princeton: Princeton University Press, 1976).

Bartunek, J., Changing interpretative schemes and organizational restructuring: The example of a religious order, Administrative Science Quaterly (1984), N²9, pp. 355-372.

Bartunek, J. and Moch, M. K., First order, second order and third order change and organizational development intervention: A cognitive approach, The Journal of Applied Behavioral Science (1987), $\mathrm{N}^{\circ}$ 23(4), pp. 483-500.

Berger, P. and Luckman T., The social construction of reality (Harmonsworth: Pengin, 1967).

Bettenhausen, K., and Murnigham, J. K., 1985, The emergence of norms in competitive decision-making groups, Administrative Science Quaterly (1985), N³0, pp. 350-372.

Bettis, R. A. and Prahalad, C. K., The dominant logic: Retrospective and extension, Strategic Management Journal (1995), $\mathrm{N}^{\circ} 16$, pp. 5-14.

Beyer, J. M., Ideologies, values and decision making in organizations. In: P.C. Nystrom et W.H. Starbuck (Eds.), Handbook of organizational design, vol 2 (London: Oxford University Press, 1981), pp.166-201.

Beyer, J. M., Dunbar, R. L. and Meyer A. D., 1988, Comment: The concept of ideology in organizational analysis, Academy of Management Review (1988), $\mathrm{N}^{\circ} 13$ (3), pp. 483-89.

Bougon, M.G., Weick K.E. and Binkhorst D., Cognitions in organizations: an analysis of the Utrecht Jazz Orchestra, Administrative Science Quaterly (1977), N²2, pp. 606-639.

Bruner, J. S. and Sherwood, V., Language and thought in infancy. In: J. P. Forgas, Social cognition, Perspectives on Everyday understanding (London: Academic Press, 1981), pp. $27-51$.

Bourgeois, L. J., Performance and consensus, Strategic Management Journal (1980), N ${ }^{\circ}$, pp. 227-248.

Bouwen, R. and Fry, R., Organizational learning and innovation, International Studies of Management and Organization (1991), N²1(4), pp.37-51.

Burnstein, E. and Vinokur, A., Testing two classes of theories about group induced shifts in individual choice, Journal of Experimental Social Psychology (1973), Nº9, pp. 123-137.

Burnstein, E., Vinokur, A., Y. Trope, Interpersonnal comparision versus persuasive argumentation: a more persuasive test of alternative explanations for group-induced shifts in individual choice, Journal of Experimental Social Psychology (1973) Nº 9, pp. 236-245.

Calder, B. J. and Schurr P. H., Attitudinal processes in organizations. In: B.M. Staws and L.L. Cummings (Eds.), Research in Organizational Behavior (Greenwich: JAI Press Inc., 1981), N 3, pp. 283-302.

Cicourel, A. V., Cognitive sociology: Language and meaning in social interaction (Harmondsworth: Penguin, 1972).

Codol, J. P., Note terminologique sur l'emploi de quelques expressions concernant les activités et processus cognitifs en psychologie sociale, Bulletin de Psychologie (1969), N²3, pp. 63-70. 
Codol, J. P., On the system of Representations in a group situation, European Journal of Social Psychology (1974), N4, pp. 343-365.

Codol, J. P., On the system of representations in an artificial social situation. In: R. M. Farr and S. Moscovici (Eds.), Social Representations (Cambridge: Cambridge university Press, 1984) pp. 239-253.

Codol, J. P., Vingt ans de cognition sociale, Bulletin de Psychologie (1989), XLII, 390, pp. 472-491.

Conlon, E. J. and Stone, T. H., Absence schema and the managerial judgement, Journal of Management (1992), $\mathrm{N}^{\circ} 18(3)$, pp. 435-454.

Cossette, P., La vision stratégique du propriétaire-dirigeant de PME: une étude de cartographie cognitive (Paper presented to the Congrès international francophone de la PME, Carthage, Tunisia, 28-30 October, 1993).

Cossette, P., Les cartes cognitives et organizations (Quebec: Les Presses Universitaires et de Laval and Les Editions Eska, 1994).

Cossette, P. and Audet, M., Mapping an idiosyncrasic Schema, Journal of Management Studies (1992), N²9(3), pp. 325-47.

Daniels, K. L., Markoczy, L., Goldberg., J., and Chernatony, L., Comparing cognitive maps (Paper presented at the First International Workshop on Managerial and Organizational Cognition, Brussels, Belgium, May, 1993).

Deconchy, J. P., Laboratory experiment and social field experimentation: An ambiguous distinction, European Journal of Social Psychology (1981), vol. 11, pp. 323-347.

Doise, W., Clemence, A., Lorenzi-Cioldi, F., Representations Sociales et Analyse des données (Grenoble: Les presses Universitaires de Grenoble, 1992).

Doise, W. and Mackie, D., On the social nature of cognition. In: J. P. Forgas, Social cognition, Perspectives on Everyday understanding (London: Academic Press, 1981), pp.53-81.

Doise, W. and Moscovici S., Les décisions de groupe. In: S. Moscovici, Psychologie Sociale (Paris: Presses Universitaires de France, 1984).

Doise, W. and Moscovici S., Conflict and consensus, a general theory of collective decisions (New York: Sage, 1994)

Doise, W. and Mugny, G., Individual and collective conflicts of centrations in cognitive development, European Journal of Social Psychology (1979), Nº, pp. 105-108.

Doms, M. and Moscovici S., Innovation et Influence des minorités. In: S. Moscovici, Psychologie Sociale (Paris: Presses Universitaires de France, 1984).

Dunn, W. D. and Ginsberg, A., A Sociocognitive Network Approach to Organizational Analysis, Human Relations (1986), №40(11), pp. 955-976.

Eden, C., Ackerman, F and , Cropper, S., The analysis of cause maps, Journal of Management Studies (1992), N $\mathrm{N}^{\circ}$ 29(3), pp. 309-324.

Eden, C., S. Jones, S., Sims, D, Messing about in problems: An informal structured approach to their identification and management, (Oxford: Pergamon Press, 1983).

Fahey, L. and Narayanan, V. K., Linking changes in revealed causal maps and environmental change: an emprical study, Journal of Management Studies (1989), N²6(4), pp. 361-378.

Feldman, D. C., The development and enforcement of group norms, Academy of Management Review (1984), n ${ }^{\circ}$ (1), pp. 47-53.

Fiol, C. M., Consensus, diversity and learning in organizations, Organization Science (1994), №5(3), pp. 403-420.

Fiol, C. M. and M. A. Lyles, Organizational learning, Academy of Management Review (1985), $\mathrm{N}^{\circ} 10(4)$, pp. 803-613.

Flament, C., Structure et dynamiques des représentations sociales. In: D. Jodelet, Les représentations sociales (Paris: Presses Universitaires de France, 1989).

Ford, J.D. and Hegarty, W.H., 1984, Decision maker's beliefs about causes and effects of structure, Academy of Management Journal (1984), N²7(2), pp. 271-291.

Forgas, J. P., Polarization and moderation of person perception judgements as function of group interaction style, European Journal of Social psychology (1977), ํㅜ ${ }^{\circ}$, pp. 175-185.

Forgas, J. P., What is social about social cognition. In: J. P. Forgas, Social Cognition, Perspectives on Everyday understanding (London: Academic Press, 1981a), pp. 1-25. 
Forgas J. P., Epilogue: Everyday understanding and social cognitionI In: J. P. Forgas, Social Cognition, Perspectives on Everyday understanding (London: Academic Press, 1981b), pp. 259-271. Fotoni-Paradissopoulos, H., Assessing the boardmembers' roles: A cognitive model for strategic decision-making (Paper Presented to the International Workshop on Managerial and Organizational Cognition, Brussels, Belgium, May 26-27, 1994).

Garud, R. and Rappa, M. A., A socio-cognitive model of technology evolution: The case of Cochlear implants, Organization Studies (1994), N5(3), pp. 344-362.

Ginsberg, A., Connecting Diversification to Performance: A sociocognitive approach, Academy of Management Review (1990), №15(3), pp. 514-535.

Gioia, D.A., and Poole, P. P., Scripts in organizational behavior, Academy of Management Review (1984), $\mathrm{N}^{\circ}$ 9(3), pp. 449-459.

Gioia, D. A., and Sims, H. P., Cognition-behavior connections: attribution and verbal behavior in leader/subordinates interactions, Organizational Behavior and Human Decision Processes (1986), N³7, pp. 503-530.

Gioia, D. A., Donnellon, A., and Sims, H. P., Communication and Cognition in Appraisal: A tale of two Paradigms, Organization Studies (1989), N¹0(4), pp. 503-530.

Gioia, D.A., Thomas, J. B., Clark, S. M. and Chittipeddi, K., Symbolism and strategic change in academia: The dynamics of sensemaking and influence, Organization Science (1994), N5(3), pp. 363-383.

Glick, W. H., Response: Organizations are not central tendencies: Shadow Boxing in the Dark, Round 2, Academy of Management Review (1988), $\mathrm{N}^{\circ} 13(1)$, pp. 133-137.

Gray, B., Bougon, M. and Donnellon A, Organizations as constructions and destruction of meaning, Journal of Management (1985), $\mathrm{N}^{\circ} 11(2)$, pp. 83-98.

Hall, R., A system pathology of an organization: the rise and fall of the Old Saturday Evening Post, Administrative Science Quaterly (1976), N²1, pp. 185-211.

Hall, R., The natural logic of management policy making: its implication for the survival of an organization, Management Science (1984), $\mathrm{N}^{\circ} 30(8)$, pp. 905-27.

Harré, R., Rituals, rhetoric and social cognition. In: J. P. Forgas, Social Cognition, Perspectives on Everyday understanding (London: Academic Press, 1981), pp. 211-224.

Harris, S. G., Organizational culture and individual sensemaking: A schema based perspective, Organization Science (1994), N5(3), pp. 309-321.

Hedberg, B. L. T., How organizations learn and unlearn. In: Nystrom P.C., W.H. Starbuck (Eds.), Handbook of organizational Design, vol 1 (New-York: Oxford University Press, 1981).

Hewstone, M., Représentations sociales et causalité. In: D. Jodelet, Les représentations sociales (Paris: Presses Universitaires de France, 1989).

Huber, G. P., Organizational Learning: The contributing processes and the literatures, Organization Science (1991), N²(1), pp. 88-115.

Huff, A. S., Mapping Strategic Thought (New York: Wiley, 1990).

Hugues, P., Asch, R. and Daniels, K., The diversity of individual level managerial mental models of competition (Paper Presented at the International Workshop on Managerial and Organizational Cognition, Brussels, Belgium, May 26-27, 1994).

Isenberg, D. I., Thinking and managing: A verbal protocol analysis of managerial problem solving, Academy of Management Journal (1986), N²9(4), pp. 775-788.

Jahoda, G., 1988, Critical Notes and Reflections on "Social Representations", European Journal of Social Psychology (1988), vol. 18, pp. 195-209.

James, L. R., Joyce, W. F. and Slocum, Comment: Organizations do not cognize, Academy of Management Review (1988), vol 13, n¹3(1), pp. 129-132.

Jaspars, J., and Hewstone, M., La théorie de l'attribution. In: S. Moscovici, Psychologie Sociale (Paris: Presses Universitaires de France, 1984).

Jenkins, M., Creating and Comparing Strategic Causal Maps: Issues in Mapping across Multiple Organizations (Paper Presented to the 2nd International Workshop on Managerial and Organizational Cognition, Brussels, Belgium, May 26-27, 1994)

Jermier, J., Slocum, J. W., Louis J. and Gaines, J., Organizational subcultures in a soft bureaucracy: Resistance behind the myth and facade of an official culture, Organization Science (1991), N ${ }^{\circ}$ (2), pp. 170-194. 
Jodelet, D., Les représentations sociales (Paris: Presses Universitaires de France, 1989).

Johnson, G., Strategic change and the management process (Oxford: Blackwell, 1986).

Kiesler, S. and Sproull, L., Managerial response to changing environment: Perspectives on problem sensing from social cognition, Administrative Science Quaterly (1982), N²7, pp. 548-570.

Koenig, G., L'Apprentissage Organisationnel: Repérage des Lieux, Revue Française de Gestion (1994), Janvier-Février, pp. 76-83

Klimoski, R., and Mohammed, S., Team Mental Model: Construct or Metaphor, Journal of Management (1994), $\quad \mathrm{N}^{\circ} 20(2)$, pp. 403-437.

Lamm, H., and Myers, D. G., The group polarization phenomenon, Psychological Bulletin (1976), $\mathrm{N}^{\circ} 83(4)$, pp. 602-627.

Laroche, H., From decision to action in organizations: decision-making as a social representation, Organization Science (1995), N¹6(1), pp.62-75.

Laroche, H. and Nioche J. P., L'approche cognitive de la stratégie d'entreprise, Revue Française de Gestion (1994), Juin-Juillet-Août, pp. 64-78

Langfield-Smith, K., Exploring the need for a shared cognitive map, Journal of Management Studies (1992), N²9(3), p. 349-368.

Laukkanen, M., Understanding the Formation of Managers' Cognitive Maps: A Comparative Case Sudy of Context Traces in Two Business Firm Clusters (Helsinki: Helsinki School of Economics and Business Administration publications, 1989).

Laukkanen, M., Comparative Cause Mapping of Management Cognitions, A computer Data Base Method for Natural Data, (Working Paper, Publications D-154, Helsinki School of Economics and Business Administration, 1992).

Laukkanen, M., 1994, Comparative Cause mapping of Organizational Cognitions, Organization Science (1994), N5(3), pp. 322-343.

Lauriol, J., Approches cognitives de la décision et concept de Représentations Sociales (Paper presented to the 3rd Conférence Internationale de Management Stratégique, Lyon, May, 1994).

Lee, S., Courtney, J. F. and O'Keefe, R. M., A system for organizational learning using cognitive maps, Omega (1992), №20(1), pp. 23-36.

Levine, J. M. and Pavelchak, M. A., Conformité et obéissance. In: S. Moscovici, Psychologie Sociale (Paris: Presses Universitaires de France, 1984).

Lord, R., An information processing approach to social perceptions, leadership and behavioral measurement in organizations. In: B.M. Staws and L.L. Cummings (Eds.), Research in organizational behavior, an annual series of analytical essays and critical reviews, vol 7 (Greenwich: JAI Press Inc, 1985).

Louis, M.L., Surprise and sense-making: what newcomers experience when entering unfamiliar organizational settings, Administrative Science Quaterly (1980), N²7, pp. 548-570.

Lyles, M. A. and Schwenk, C. R., Top management, strategy and organizational knowledge structures, Journal of Management Studies (1992), N²9(2), pp. 155-174.

Marc, E. and Picard, D., L'interaction sociale (Paris: Presses Universitaires de France, 1989).

Markoczy, L., and Goldberg, J., A method for eliciting and Comparing Causal Maps (Paper presented to the First International Workshop on Managerial and Organizational Cognition, Brussels, Belgium, May 1993).

Montgomery, H. and Svenson, O., Process and structure in human decision making (London: John Wiley \& Sons, 1989).

Moscovici, S., Toward a theory of conversion behavior. In: L. Berkowitz (Eds.), Advances in experimental social psychology, vol 13 (New York:Academic Press, 1981), pp. 209-239.

Moscovici, S., Psychologie sociale (Paris: Presses Universitaires de France, 1984a).

Moscovici, S., The phenomenon of Social Representations. In: R. M. Farr and S. Moscovici, Social Representations (Cambridge: Cambridge university Press, 1984b), pp. 3-69.

Moscovici, S., Notes towards a description of Social Representations, European Journal of Social Psychology (1988), N¹8, pp. 211-250.

Moscovici, S., Des représentations collectives aux représentations sociales: Eléments pour une histoire, In: D. Jodelet, Les représentations sociales (Paris: Presses Universitaires de France, 1989). 
Moscovici, S. and Faucheux, C., Social influence, conformity bias, and the study of active minority. In: L. Berkowitz (Eds.), Advances in experimental social psychology, vol 6 (New York: Academic Press, 1972), pp. 149-202.

Moscovici, S. and Lage, E., Studies in social influence III: Majority versus minority influence in a group, European Journal of Social Psychology (1976), №6, pp. 149-174.

Moscovici, S. and Lage, E., Studies in social influence IV: Minority influence in a context of original judgement, European Journal of Social Psychology (1978), Nº 8, pp. 349-365.

Moscovici, S., Lage, E. and Naffrechoux, N., Influence of a consistent minority on the responses of a majority in a color perception task, Sociometry (1969), №32, pp. 365-379.

Moscovici, S., Mugny, G. and Papastamou, S., "Sleeper-effect" et/ou effet minoritaire? Etude théorique et expérimentale de l'influence sociale à retardement, Cahiers de Psychologie Cognitive (1981), N¹, pp. 199-221.

Moscovici, S., and Neve P., Studies in Social influence I: Those who are absent are in the right: Convergence and Polarization of answers in the course of Social Interactions, European Journal of Social Psychology (1971), N¹(2), pp. 201-214.

Moscovici, S. and Zavalloni, M., The group as polarizer of attitudes, Journal of Personality and Social Psychology (1969), $\mathrm{N}^{\circ} 12(2)$, pp. 125-135.

Mugny, G. and Papastamou, S., A propos du "crédit idyosyncrasique" chez Hollander: Conformisme initial ou négociation?, Bulletin de psychologie (1975), $\mathrm{N}^{\circ} 29$, pp. 970-976.

Mugny, G. and Papastamou, S., When rigidity does not fail: Individualization and psychologisation as resistances to the diffusion of minority innovations, European Journal of Social Psychology (1979), $\mathrm{N}^{\circ}$, pp. 43-61.

Mugny, G., Pierrehumbert, B., and Zubel, R., Le style d'interaction comme facteur de l'influence sociale, Bulletin de Psychologie (1972), №26, pp. 789-793.

Myers, D. G. and Bishop G. D., Enhancement of dominant attitudes in group discussion, Journal of personality and social psychology (1971), vol 20, N²0(3), pp. 386-391.

Neve, P. and Gautier, J. M., Phénomènes de polarisation des décisions de groupe: Etude expérimentale des effets de l'implication, Bulletin de Psychologie (1977), №31, pp. 361-370.

Nystrom, P. C. and Starbuck, H., Managing beliefs in organizations, The Journal of Applied Behavioral Science (1984) N²0(3), pp. 277-287.

Paicheler, G., Polarization of attitudes in homogeneous and heterogeneous groups, European Journal of Social Psychology (1978), Nº, pp. 85-96.

Paicheler, G., Argumentation, Négociation et polarisation, Bulletin de Psychologie (1979), ํ31, pp. 923-31.

Paicheler, G. and Moscovici, S., Suivisme et conversion. In: S. Moscovici, Psychologie sociale (Paris: Presses Universitaires de France, 1984).

Pfeffer, J., 1981, Management as Symbolic Action: The Creation and Maintenance of Organizational Paradigms. In: B.M. Staws and L.L. Cummings (Eds.), Research in Organizational Behavior, an annual series of analytical essays and critical reviews, (Greenwich: JAI Press Inc., 1981), N³, pp. $1-52$

Pfeffer, J., and Salancik, G. R., A Social Information Processing Approach to Job Attitudes and Task Design, Administrative Science Quaterly (1978), N23, June, pp. 224-253.

Poole, P. P., Gioia, D. A. and Gray, B., Influence modes, schema change, and organizational transformation, The Journal of Applied Behavioral Science (1989), vol 25, n²5(3), pp. 271-289.

Porac, J., Thomas, H. and Baden Fuller, C., Competitive groups as cognitive communities: The case of Scottish Knitwear manufacturers, Journal of Management Studies (1989), N26(4), pp. 397-416.

Prahalad, C.K. and Bettis, R. A., The dominant logic: a new linkage between diversity and performance, Strategic Management Journal (1986), Nº, pp. 485-501.

Rentsch, J. R., Climate and Culture: Interaction and qualitative differences in organizational meanings, Journal of Applied Psychology (1990), n 75(6), pp. 688-681.

Rousseau, D. M., Issues of level in organizational research: Multi-level and cross-level perspectives. In: B.M. Staws and L.L. Cummings (Eds.), Research in organizational behavior, an annual series of analytical essays and critical reviews, vol 7, (Greenwich: JAI Press Inc., 1985), pp. 1-37. 
Sapienza, A. M, Believing is seeing,: How Culture Influences the Decisions Top Managers Make in R. Kilmann, M. J. Saxton, R. Serpa et al. (Eds.), Gaining Control of Corporate Culture, (San Francisco: Jossey-Bass, 1985), pp. 66-83.

Sawy, O. A., Pauchant, T. C., 1988, Triggers, Templates and Twitches in the Tracking of Emerging Strategic Issues, Strategic Management Journal (1988), Nº , pp. 455-473.

Schein, E. H., Coming to a New Awareness of Organizational Culture, Sloan Management Review (1984), Winter, pp. 3-16.

Schneider, S. C. and Angelmar, R., Cognition in organizational analysis: Who's Minding the Store?, Organization Studies, (1993), N${ }^{\circ}$ (4(3), pp. 347-374.

Schneider, S., and Shrivastava, P., Basic Assumptions Themes in Organizations, Human Relations (1987), N41(7), pp. 493-516.

Schön, D. A., Organizational Learning. In: Morgan (Eds.), Beyond method, a study of organizational research strategies (NewYork: Sage, 1983), pp. 114-127.

Schweiger, D. M., Sandberg W. R. and Ragan, J. W., Group approachs for improving strategic decision-making: a comparative analysis of dialectical inquiry, devil's advocacy and consensus, Academy of Management Journal (1986), №29(1), pp. 51-71.

Schwenk, C. R., Linking cognitive, organizational and political factors in explaning strategic change, Journal of Management studies (1989), №26(2), pp. 177-187.

Shrivastava, P., A typology of Organizational learning systems, Journal of Management Studies (1983), $\mathrm{N}^{\circ} 20(1)$, pp. 7-29.

Shrivastava, P. and Schneider, S., Organizational frames of references, Human Relations (1984), $\mathrm{N}^{\circ} 37(10)$, pp. 795-809.

Smircich, L., Concepts of culture and organizational analysis, Administrative Science Quaterly (1983), $\mathrm{N}^{\circ} 28$, p. 339-358.

Smircich, L., and Stubbart, C., Strategic Management in an Enacted World, Academy of Management Review (1985), $\mathrm{N}^{\circ} 10(4)$, pp. 724-736.

Spender, J. C., Workplace Knowledge: the Individual and Collective Dimensions, (Paper Presented at the International Workshop on Managerial and Organizational Cognition, Brussels, Belgium, May 26-27, 1994).

Sperber, D., L'étude anthropologique des représentations: Problèmes et perspectives. In: D. Jodelet, Les représentations sociales (Paris, Presses Universitaires de France, 1989).

Sproull, L.S., Beliefs in Organizations. In: P.C. Nystrom and W.H. Starbuck (Eds.), Handbook of organizational design, vol 2, (London: Oxford University Press, 1981).

Starbuck, W.H., Congealing oil: inventing ideologies to justify ideologies out, Journal of Management Studies (1982), $\mathrm{N}^{\circ} 19(1)$, pp. 3-27.

Stubbart, C. I., Managerial Cognition: A Missing Link in Strategic Management Research, Journal of Management Studies (1989), N²6(4), pp. 325-347.

Stubbart, C., What is managerial and organizational cognition? (Paper Presented to the International Workshop on Managerial and Organizational Cognition, Brussels, Belgium, May 13-14, 1993).

Thomas, J. B., Clark, S. M. and Gioia, D. A., Strategic sensemaking and organizational performance: Linkages among scanning, interpretation, actions and outcomes, Academy of Management Review (1993), $\mathrm{N}^{\circ} 36(2)$, pp. 239-70.

Vergès, P., Grize, J. B. and Silem, A., Représentations sociales et logiques naturelles. In: Salariés face aux nouvelles technologies: Vers une approche socio-logique des représentations sociales (Paris: Editions du CNRS, Paris, 1987)

Vinokur, A. and Burnstein, E., Novel argumentation and attitude change: the case of polarization following group discussion, European Journal of Social Psychology (1976), №6, pp. 335-346.

Vinokur, A., Trope, Y. and Burnstein, E., A decision making analysis of persuasive argumentation and the choice shift effect, Journal of Experimental Social Psychology (1975), $\mathrm{N}^{\circ} 11$, pp. 125-148.

Von Krogh, G., Roos, J. and Slocum, K., An essay on corporate epistemology, Strategic Management Journal (1995), №15, pp. 53-71.

Walsh, J.P. and Fahey, L., The role of negotiated belief structures in strategy making, Journal of Management (1986), $\mathrm{N}^{\circ} 12(3)$, pp. 325-338. 
Walsh, J.P., Henderson, C. M. and Deighton, C. M., Negotiated belief structures and decision performance: an empirical investigation, Organizational Behavior and Human Decision Processes (1988), $\mathrm{N}^{\circ} 42$, pp. 194-216.

Walton, E., Managers' Prototypes of financial terms, Journal of Management Studies (1986), ํ23(6), pp. 679-698.

Ward, J. C. and Reingen, P. H., Socio-cognitive analysis of group decision-making among consumers, Journal of Consumer Research (1990), N¹7, pp. 245-262.

Weber, R. P., Basic content analysis, (Newbury Park: Sage University Papers, 1990).

Weick, K. E. and Bougon, M. G, Organizations as cognitive maps, Charting ways to success and failure. In: H. P. Sims, D. A. Gioia and Associates (Eds.), The Thinking Organization (London: Jossey Bass Publishers, 1986), pp. 102-135.

Whitney, J.C. and Smith, R. A., Effects of Group cohesiveness on attitude polarization of knowledge in a strategic planning context, Journal of Marketing Research (1983), ํ20, pp. 167-176.

Windish, U., Représentations sociales, sociologie et sociolinguistique: L'exemple du raisonnement et du parler quotidien. In: D. Jodelet, Les représentations sociales (Paris: Presses Universitaires de France, 1989).

Yin, R. K., Case study research, design and methods, Applied social research methods, (Newbury Park: Sage Publications, 1990). 